\title{
Identification of immunodominant antigens in canine leptospirosis by Multi-Antigen Print ImmunoAssay (MAPIA)
}

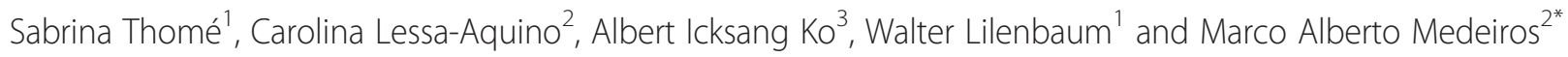

\begin{abstract}
Background: The microscopic agglutination test (MAT), the standard method for serological diagnosis of leptospirosis, may present limitations regarding its sensitivity. Current studies suggest that Leptospira immunoglobulin-like (Lig) proteins and LipL32 are of particular interest as serodiagnostic markers since they are present only in pathogenic species of the Leptospira genus. The purpose of this study was to identify leptospiral immunodominant proteins that are recognized by canine sera from diseased dogs.

Results: A total of 109 dogs were studied, including seroreactive dogs (MAT $\geq 800$ ) and dogs with no seroreactivity detectable by MAT. Eight recombinant fragments (31-70 kDa) of pathogenic Leptospira were tested for their use as diagnostic markers for canine leptospirosis using the Multi-antigen Print Immunoassay (MAPIA) platform: LigB [582-947aa] from L. interrogans serovar Pomona, L. interrogans serovar Copenhageni and L. kirschneri serovar Gryppotyphosa, LigB [131-649aa] from L. interrogans serovar Copenhageni, L. interrogans serovar Canicola and L. kirschneri serovar Gryppotyphosa, LigA [625-1224aa] L. interrogans serovar Copenhageni and LipL32 from L. interrogans serovar Copenhageni. The data were analyzed and ROC curves were generated. Altogether, LigB [131-649aa] L. interrogans Canicola, LigB [131-649aa] L. kirschneri Gryppotyphosa and LipL32 L. interrogans Copenhageni showed best accuracy (AUC $=0.826$ to 0.869 ), with $70 \%$ specificity and sensitivity ranging from $89 \%$ to $95 \%$.
\end{abstract}

Conclusions: These results reinforce their potential as diagnostic candidates for the development of new methods for the serological diagnosis of canine leptospirosis.

Keywords: Leptospirosis, Dogs, MAPIA, LipL32, Lig proteins

\section{Background}

Leptospirosis in dogs may manifest with a wide range of symptoms, from fever to liver and kidney failure, jaundice and bleeding. It is a widespread life-threatening disease with zoonotic potential, particularly in tropical areas [1,2], where characteristics such as climate, topography and also regularity of veterinary assistance affect the prevalence of the disease [3].

The early diagnosis becomes a priority for allowing therapeutic incursions and more effective control measures [4]. However, the most employed serological method for the diagnosis of leptospirosis - the microscopic agglutination test (MAT) - may not present adequate sensitivity,

\footnotetext{
* Correspondence: medeiros@bio.fiocruz.br

${ }^{2}$ Fiocruz, Bio-Manguinhos, Laboratory of Recombinant Technology, Avenida Brasil, 4365, Manguinhos, 21045-900 Rio de Janeiro, RJ, Brasil

Full list of author information is available at the end of the article
}

particularly in detecting early disease. Additionally, it requires specific laboratory facilities and is too laborious, offering risk to the operator [5]. The MAT detects agglutinating antibodies and paired serum samples with an interval of at least 10 days are needed to diagnose acute infection [6]. Due to these limitations, recent studies have applied proteomic approaches in order to identify novel protein antigens for the development of alternative diagnostic tests [7]. Currently, a variety of alternative methods based on recombinant proteins are under development, such as ELISAs and immunoblotting assays, and have shown encouraging results $[8,5,9,10]$.

Several reported serodiagnostic assays target the leptospiral immunoglobulin-like (Lig) proteins as antigen [10]. It has been demonstrated that the lig genes are highly conserved among different leptospiral species and present exclusively among pathogenic leptospires [11]. Besides, 
the lig proteins are exposed on the surface of the bacterium and have been identified not only as diagnostic markers during early leptospirosis but also as potential candidates for vaccine development $[8,12]$. Additionally, LipL32 is also a protein with remarkable importance in this context, since it is the most abundant outer membrane lipoprotein of leptospires and seems to be highly immunogenic [13,14].

The purpose of this study was to identify immunodominant proteins of leptospires that are recognized by sera from healthy or diseased dogs, which can be employed in the development of a novel diagnostic test for canine leptospirosis.

\section{Results}

According to the MAT results, reactions against members of serogroup Icterohaemorrhagiae (serovars Icterohaemorrhagiae and Copenhageni) were the most common, representing $86.7 \%(26 / 30)$ of all seroreactive samples. Seroreactivity against serogroups pomona $(10 \%, 3 / 30)$ and grippotyphosa $(3.3 \%, 1 / 30)$ were also detected.

The purified recombinant proteins used for printing the MAPIA strips were analyzed by SDS PAGE 12.5\% and showed high homogeneity (Figure 1). The MAPIA densitometry results showed that, in general, group N2 (housed vaccinated dogs) had lower IgM background against the recombinant proteins than groups N3 (stray dogs) and N4 (dogs with other febrile syndromes) and group P1 (seropositive dogs) had a stronger IgM reactivity (Figure 2). The reactivity detected for group P1 (seropositive dogs) against LigB [131-649aa] L. kirschneri Gryppotyphosa, LigB [131-649aa] L. interrogans Canicola and LipL32 L. interrogans Copenhageni were the most intense, with a higher median reactivity when compared to the control groups (Figure 2).

Using a cut-off of 1.5 standard deviations above the average reactivity of the control samples, we were able to establish sensitivity and specificity values for each of the recombinant proteins studied when comparing the seropositive group (P1) with each of the control groups (N2, N3 and N4). The results are summarized in Table 1. The specificity did not vary significantly when analyzing the different control groups. Conversely, sensitivity varied considerably, showing lower values when group N3 (stray dogs) was the considered group. Even though sensitivity is strictly related to the number of true positive samples, that is, reactivity among the reference samples in group P1, the use of different control groups lead to different cut-offs, which may ultimately influence the sensitivity. Indeed, background reactivity was higher in group N3 (Figure 2), increasing the cut-off value compared to groups N2 and N4 (Table 2). In general, Lig recombinant proteins [131-649aa] L. interrogans Canicola, Lig [131-649aa] L. kirschneri Gryppotyphosa and LipL 32 L. interrogans

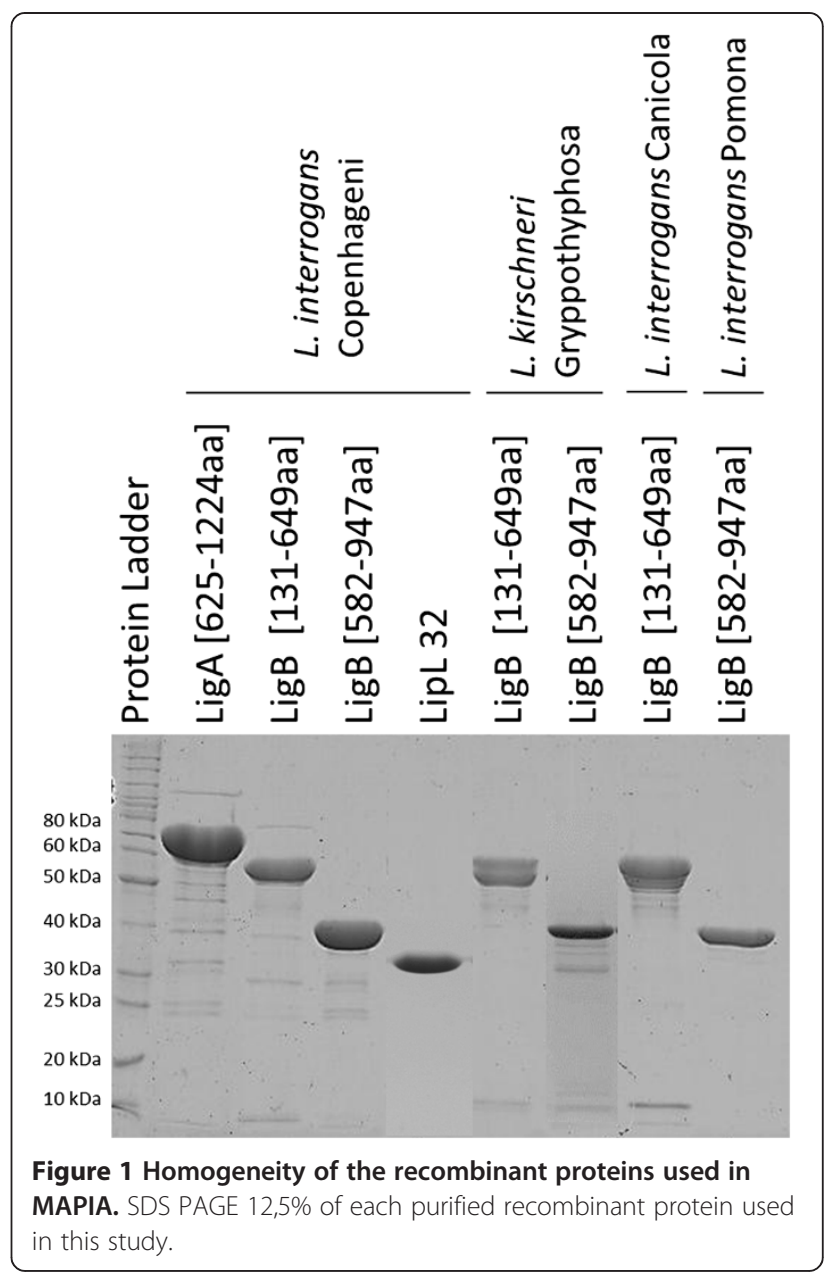

Copenhageni provided best sensitivity rates, for all control groups, except for group N3, in which Lig [131-649aa] $L$. interrogans Copenhageni overpassed LipL32.

In order to assess the diagnostic accuracy of the recombinant proteins, individual antigen ROC curves were generated and the corresponding AUC was determined. Antigens were then ranked by decreasing AUC and multiple antigens ROC curves were generated. Figure 3A shows the individual ROC curves for each of the recombinant proteins when we compared the seropositive dogs (group P1) against all the other groups combined as a single group (groups N2, N3 and N4). The AUC values are shown in Table 1. LipL32 L. interrogans Copenhageni provided best accuracy (AUC $=0.869$ ), followed by $\operatorname{LigB}$ [131-649aa] L. kirschneri Gryppotyphosa $(\mathrm{AUC}=0.855)$ and LigB [131-649aa] L. interrogans Canicola (AUC = 0.826). Furthermore, when group P1 was compared to groups N2, N3 and N4 separately, the same antigens showed best performance. The combination of those three antigens improved the diagnostic accuracy when considering all control samples in a single group (Figure 3B) and also when group P1 was compared to group N3 (stray 


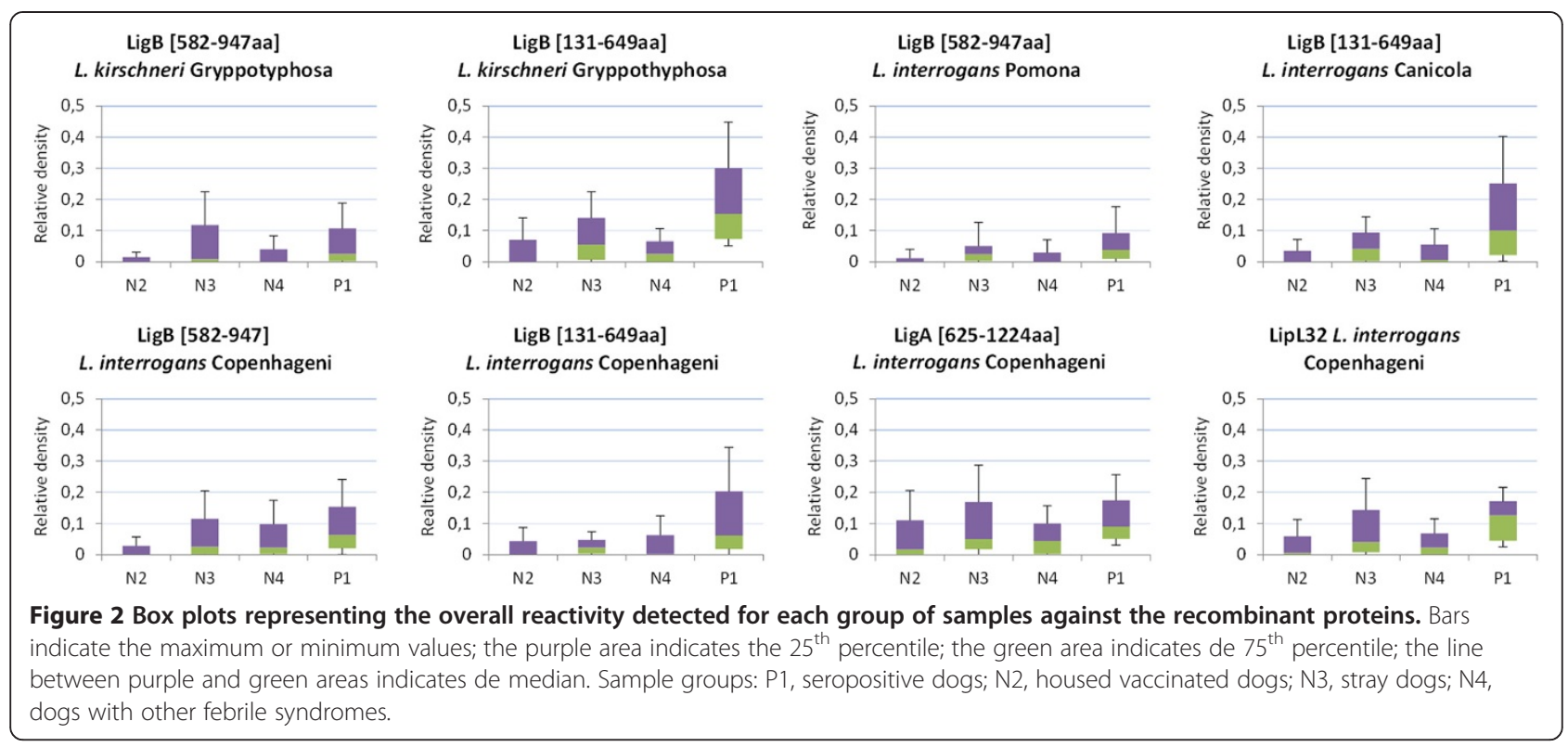

dogs, Figure 4). Using group N2 as the control group, LipL32 and LigB [131-649aa] L. kirschneri Gryppotyphosa provided the best performance. When we consider group N4 (dogs with other febrile syndromes) as control, however, the addition of extra antigens did not impact the diagnostic performance of LipL32 (Figure 4).

\section{Discussion}

In the present study we used three different groups of seronegative samples. Group N2 was a very well-defined group, with reliable information regarding shelter, immunization and veterinary assistance. Although Rio de Janeiro, as other tropical cities, is an endemic city for leptospirosis and it is not possible to exclude the possibility of previous contact of those dogs with leptospires, those animals present a low epidemiological risk of infection due to smaller chances of direct or indirect contact with rodents. Accordingly, higher sensitivity and specificity rates were obtained when the seropositive group P1 was compared against group N2. It is also interesting to highlight that all animals in group $\mathrm{N} 2$ had been vaccinated within 1 year before sample collection and, therefore, the antigens with high diagnostic performance identified when group N2 was used as control were actually able to differentiate between a current acute leptospirosis case and a vaccinated non-diseased dog.

Conversely, animals from Group N3 (stray dogs) presented the lower accuracy results. Information regarding the epidemiological status of those animals was very scarce, as well as data about previous diseases or immunizations history. Therefore, those dogs may have been exposed to many variables, and possible biases cannot be excluded. Nevertheless, it is important to note that in the daily practice information may not be available for the practitioner when a decision regarding the diagnostic test must be taken. In that situation, results of group N3 represent a non-ideal but very common scenario in veterinary practice, justifying its inclusion in the present study.

Table 1 Diagnostic performance of each antigen for all the control groups studied

\begin{tabular}{|c|c|c|c|c|c|c|c|c|}
\hline \multirow[t]{2}{*}{ Antigens } & \multicolumn{2}{|c|}{ P1 vs N2 } & \multicolumn{2}{|c|}{ P1 vs N3 } & \multicolumn{2}{|c|}{ P1 vs N4 } & \multicolumn{2}{|c|}{ P1 vs N2, N3 and N4 combined } \\
\hline & $\overline{A U C}$ & $\overline{\mathrm{Se} / \mathrm{Spe}}$ & $\overline{A U C}$ & $\overline{\mathrm{Se} / \mathrm{Spe}}$ & $\overline{\text { AUC }}$ & Se/Spe & $\overline{A U C}$ & Se/Spe \\
\hline LigB [582-947aa] L. interrogans Pomona & 0.841 & $63 / 90$ & 0.636 & $27 / 90$ & 0.781 & $43 / 89$ & 0.749 & $40 / 90$ \\
\hline LigB [131-649aa] L. interrogans Canicola & 0.879 & $73 / 87$ & 0.763 & $53 / 93$ & 0.840 & $70 / 89$ & 0.826 & $67 / 91$ \\
\hline LigB [582-947aa] L. interrogans Copenhageni & 0.875 & $67 / 90$ & 0.682 & $27 / 90$ & 0.704 & $33 / 95$ & 0.764 & $37 / 91$ \\
\hline LigB [131-649aa] L. interrogans Copenhageni & 0.827 & $63 / 87$ & 0.707 & $47 / 87$ & 0.811 & $57 / 89$ & 0.777 & $50 / 87$ \\
\hline LigA [625-1224aa] L. interrogans Copenhageni & 0.875 & $63 / 93$ & 0.654 & $20 / 90$ & 0.714 & $40 / 95$ & 0.764 & $37 / 89$ \\
\hline LipL32 L. interrogans Copenhageni & 0.951 & $77 / 93$ & 0.787 & $43 / 93$ & 0.869 & $70 / 95$ & 0.869 & $60 / 91$ \\
\hline LigB [582-947aa] L. kirschneri Gryppotyphosa & 0.759 & $63 / 90$ & 0.601 & $27 / 97$ & 0.742 & $53 / 89$ & 0.695 & $40 / 92$ \\
\hline LigB [131-649aa] L. kirschneri Gryppotyphosa & 0.919 & $80 / 93$ & 0.787 & $57 / 93$ & 0.861 & $70 / 89$ & 0.855 & $63 / 90$ \\
\hline
\end{tabular}

Se: sensitivity; Spe: specificity. Sample groups: P1, seropositive dogs; N2, housed vaccinated dogs; N3, stray dogs; N4, dogs with other febrile syndromes. 
Table 2 Established cut-off for each of the proteins and control groups used in this study

\begin{tabular}{|c|c|c|c|c|c|c|c|c|}
\hline \multirow[t]{2}{*}{ Sera } & \multicolumn{6}{|l|}{ L. interrogans } & \multicolumn{2}{|l|}{ L. kirschneri } \\
\hline & $\begin{array}{l}\text { LigB [582-947aa] } \\
\text { Pomona }\end{array}$ & $\begin{array}{l}\text { LigB [131-649aa] } \\
\text { Canicola }\end{array}$ & $\begin{array}{l}\text { LigB [582-947aa] } \\
\text { Copenhageni }\end{array}$ & $\begin{array}{l}\text { LigB [131-649aa] } \\
\text { Copenhageni }\end{array}$ & $\begin{array}{l}\text { LigA [625-1224aa] } \\
\text { Copenhageni }\end{array}$ & $\begin{array}{l}\text { LipL32 } \\
\text { Copenhageni }\end{array}$ & $\begin{array}{l}\text { LigB [582-947aa] } \\
\text { Gryppothyphosa }\end{array}$ & $\begin{array}{l}\text { LigB [131-649aa] } \\
\text { Gryppothyphosa }\end{array}$ \\
\hline \multicolumn{9}{|c|}{ MAT-negative dog groups } \\
\hline N2 & 0.024 & 0.033 & 0.023 & 0.034 & 0.076 & 0.044 & 0.010 & 0.051 \\
\hline N3 & 0.079 & 0.087 & 0.101 & 0.072 & 0.180 & 0.127 & 0.072 & 0.134 \\
\hline N4 & 0.046 & 0.052 & 0.081 & 0.050 & 0.111 & 0.077 & 0.025 & 0.086 \\
\hline \multicolumn{9}{|c|}{ MAT-negative dog groups combined } \\
\hline Groups N2, N3, N4 & 0.056 & 0.064 & 0.075 & 0.055 & 0.134 & 0.092 & 0.046 & 0.100 \\
\hline
\end{tabular}

Sample groups: P1, seropositive dogs; N2, housed vaccinated dogs; N3, stray dogs; N4, dogs with other febrile syndromes. 


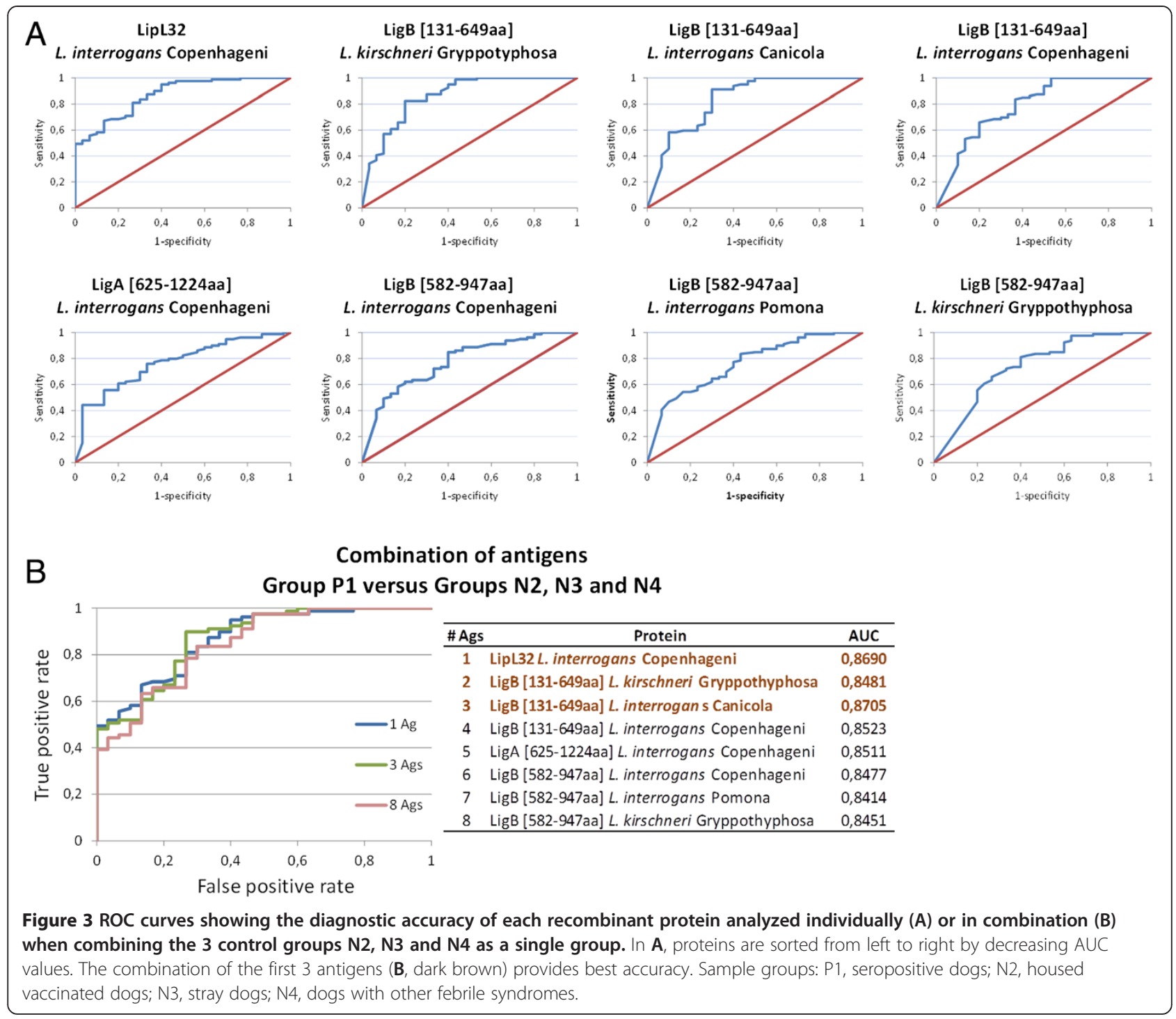

Noteworthy that in all comparative prospectuses LipL32 presented good results and discriminatory abilities. Although its potential for diagnosis tests is still controversial, the protein is known to be an immunodominant antigen in leptospirosis, particularly for the acute syndrome of the disease in human beings [12,15-17]. It has been reported that IgM antibodies specific to the C-terminal region of LipL32 can be detected during the acute infection, so that LipL32 could be effectively used as a diagnostic marker [18]. Furthermore, it has been successfully employed as an amplification target in molecular diagnosis (PCR) in human and animal samples, with excellent specificity, since it is present exclusively in pathogenic leptospires [19,20].

LipL32 alone or associated to LigB [131-649aa] of $L$. interrogans Canicola and/or L. kirschneri Gryppotyphosa showed the best discriminatory potential. The fragment LigB [131-649aa] of $L$. interrogans Canicola and/or $L$. kirschneri Gryppotyphosa is encoded by a genetic region (131-649aa) that shares $100 \%$ identity with LigA. Though LigA is present only in L. interrogans and L. kirschneri, LigB has been detected in all pathogenic Leptospira species [11]. Furthermore, the fragment LigB [131-649aa] has been described as a highly sensitive marker for leptospirosis in humans, particularly in the first week of the course of infection [8].

Our findings for canine leptospirosis are in contrast with recent studies conducted in human beings, in which the LigB [582-947aa] and LigA [625-1224] proteins were the basis of a novel rapid test and showed promising results [9]. Here, we show that those fragments are not as strongly antigenic in dogs.

The predominance of seroreactivity against serogroup icterohaemorrhagiae detected by MAT was expected and agrees with previous studies conducted with clinically suspect Brazilian dogs [21]. As a consequence, even though it was not the original purpose of this study, the MAPIA 

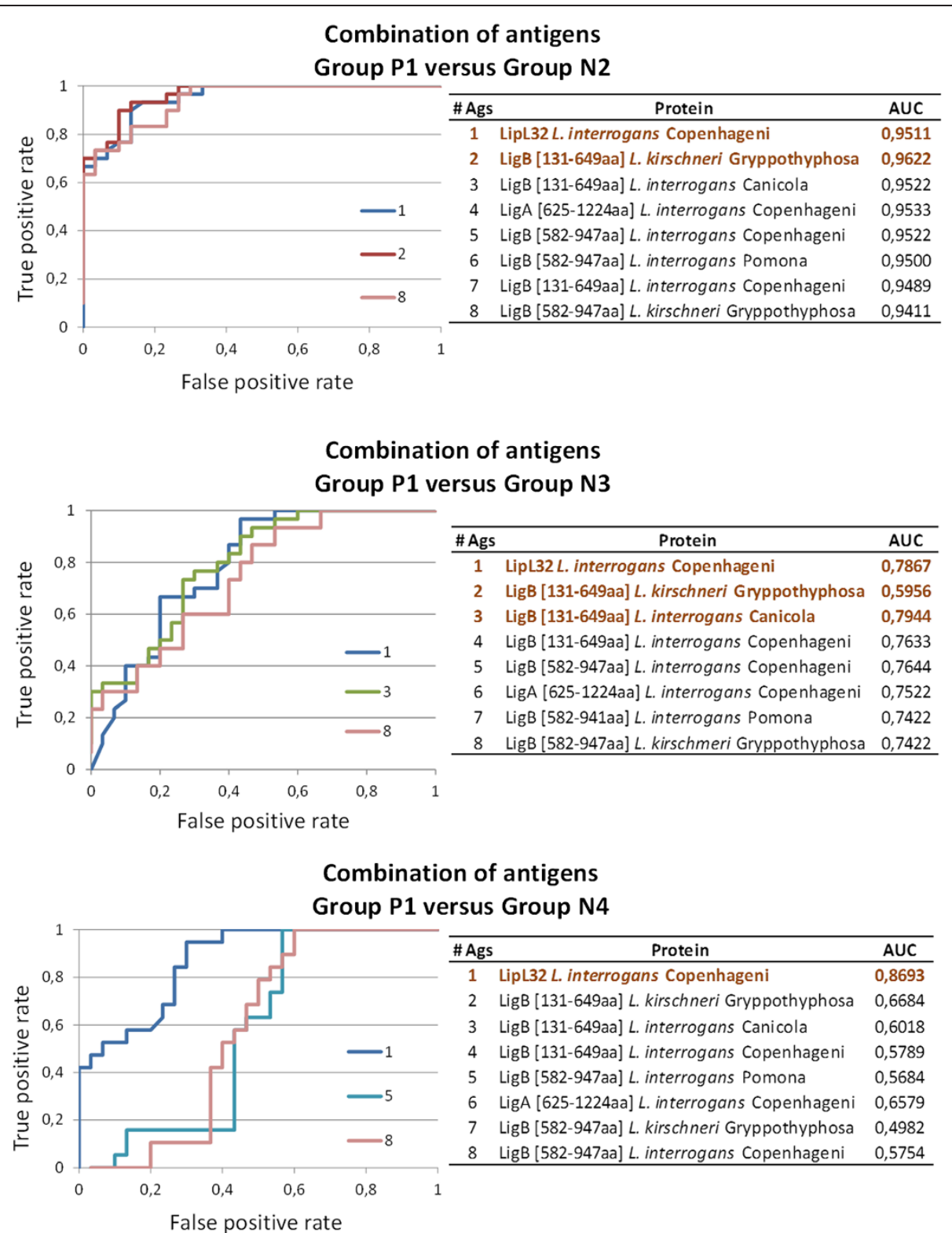

Figure 4 ROC curves showing the diagnostic accuracy of the recombinant proteins when analyzed in combination. Proteins were ranked by decreasing individual AUC and the impact of adding antigens, one at a time, was analyzed. The best combination is shown in dark brown. Sample groups: P1, seropositive dogs; N2, housed vaccinated dogs; N3, stray dogs; N4, dogs with other febrile syndromes.

analysis performed here took into account the incidental syndrome of canine leptospirosis. Therefore, it is important to highlight that our results may not represent the chronic/subclinical disease that is determined by the host-adapted serovar Canicola. It is interesting, though, the fact that LigB [131-649aa] of L. kirschneri Gryppotyphosa and L. interrogans Canicola presented better results than LigB [131-649aa] L. interrogans Copenhageni. Although theoretically a protein obtained from Copenhageni strains should be more useful for detecting dogs infected by icterohaemorraghiae serogroup, it was not observed in the current study. Noteworthy that LigB obtained from L. kirschneri has a 91\% identity with respect to $L$. interrogans serovar Copenhageni [11], and the region between amino acids 131-649aa of LigB fragment corresponding to LigB domains 2-6 has an even higher identity (96\%), which could possibly explain the obtained results.

\section{Conclusions}

MAPIA identified important immunodominant antigens in canine leptospirosis. LipL32 presented the most consistent 
results in all analysis, and may represent a major candidate for diagnostic tests. Alternatively, LigB [131-649aa] of $L$. interrogans Canicola and L. kirschneri Gryppotyphosa may increase accuracy when present in a combined antigenic formula for detecting leptospirosis in dogs.

\section{Methods \\ Study design}

Canine serum samples were collected in veterinary hospitals in Rio de Janeiro, Brazil. After collection, MAT was conducted as described later in this section in order to determine dog's sero-reactivity to leptospires. Samples were grouped according to patient's data provided by the assistant veterinarian (when available) regarding anamnesis, clinical presentation and vaccination history; and on the MAT results. Finally, the Multi-antigen Print Immunoassay (MAPIA) was performed and the samples' reactivity to different recombinant proteins of the pathogenic strains Leptospira interrogans serovar Copenhageni, Pomona and Canicola and Leptospira kirschneri serovar Gryppotyphosa was evaluated.

\section{Ethics statement}

The study protocol was approved by the Ethics Committee on Animal Use at Fluminense Federal University, Brazil (Protocol 154/2011). Written or verbal consent from the owners of the dogs was received to use blood in this study.

\section{Animal}

Blood samples were obtained from 109 adults 2-17y, including (i) 30 sero-reactive dogs with MAT titer $\geq 800$, showing clinical signs compatible with anorexia, fever, dehydration and icterus (based on the clinician's judgment) and which may or may not have been vaccinated (Group P1); (ii) 30 housed non-diseased dogs with titer $\leq 100$, which had been vaccinated (commercial bacterins) in the last year and showed no clinical alteration, so considering this group as healthy vaccinated animals (Group N2); (iii) 30 stray dogs with MAT titer $\leq 100$ and unknown history of vaccination, considering this group as unvaccinated healthy animals (Group N3), and (iv) 19 dogs sero-negative for leptospirosis (MAT titer $\leq 100$ ) but presenting a different febrile syndrome (Group N4), as canine distemper disease $(n=1)$, ehrlichiosis $(n=8)$, anaplasmosis $(n=6)$ or babesiosis $(\mathrm{n}=4)$. The febrile syndromes were diagnosed by reference laboratories through the direct detection of the pathogenic agent on blood and/or commercial ELISA serological tests. Animals' informations are summarized in Table 3. The diseases have similar clinical alterations to leptospirosis, justifying the importance of this group in the study.

The blood was withdrawn from cephalic vein. Serum was then separated by centrifugation and stored at $-20^{\circ} \mathrm{C}$ until use.

\section{Microscopic agglutination test}

For detection of anti-Leptospira antibodies, microscopic agglutination test (MAT) was conducted according to the recommendations for international standards [22]. The complete panel included 28 serovars representing all the 24 known serogroups (from Royal Tropical Institute KIT, Amsterdam, Netherlands). Bacteria were cultured in liquid Ellinghausen-McCullough-Johnson-Harris (EMJH) and used as antigens. Each serum sample was initially diluted 1:50 in buffered saline and 50 uL of this solution were transferred into vinyl microplates containing 96 wells (Corning Incorporated, Corning, NY, USA). Immediately after, an equal volume of each antigen was added to the corresponding well, with a final dilution of 1:100. The microplates were incubated at $37^{\circ} \mathrm{C}$ for 90 minutes and observed under dark-field microscopy. Serum samples were initially analyzed at a dilution of 1:100, and those that showed agglutination level equal to or higher than $50 \%$ were then diluted again in a geometrical ratio of two (1:200, 1:400 and 1:800). Samples were considered as reactive when reached titers of 200 or 400 . Reactions that presented titres $\geq 800$ were considered as strongly reactive and considered as an indication of acute infection [22].

\section{Cloning, expression and purification of recombinant proteins}

DNA fragments obtained by PCR amplification were cloned into the pET100-TOPO plasmid (Invitrogen) for the expression of recombinant proteins containing an $\mathrm{N}$-terminal $\mathrm{His}_{6}$ tag. All plasmid constructs were confirmed by DNA sequencing using an ABI 3100 sequencer (Applied Biosystems). The Lig plasmid constructs were cultured at $37^{\circ} \mathrm{C}$ to the mid-log phase, and expression was induced using isopropyl- $\beta$-D-thiogalactopyranoside (IPTG) at a final concentration of $1 \mathrm{mM}$. The cultures were then

Table 3 Groups of canine serum samples used in this study

\begin{tabular}{lllllll}
\hline Group & \# serum samples & Diagnosis & MAT titer & Housing & Age range (years) & \# vaccinated dogs in the last year \\
\hline P1 & 30 & Leptospirosis & $\geq 800$ & N/A & $2-17$ & 4 \\
N2 & 30 & Healthy & $\leq 100$ & Yes & $2-16$ & 30 \\
N3 & 30 & Healthy & $\leq 100$ & No & N/A & 0 \\
N4 & 19 & Other febrile syndromes & $\leq 100$ & N/A & $2-15$ & 18 \\
\hline
\end{tabular}


grown at $28-30^{\circ} \mathrm{C}$, depending on the protein. Cells were harvested by centrifugation at 10,000xg and resuspended in $20 \mathrm{mM}$ Tris, $1 \mathrm{mM}$ EDTA pH 8.0 and $0.1 \%$ Triton X-100. After incubating for 30 minutes at $4^{\circ} \mathrm{C}$, the cells were disrupted by sonication (Sonics \& Material). The lysate was centrifuged at $10,000 \times g$ for 20 minutes at $4^{\circ} \mathrm{C}$. The recovered soluble fraction was applied to a $\mathrm{Ni}^{2+}$-charged column (Histrap HP, GE Healthcare) in a High pressure liquid chromatography (HPLC) system and washed with 10 column volumes of buffer (PBS, pH 7.4, $20 \mathrm{mM}$ imidazole). The following stages had been made using steps varying from to $20 \mathrm{mM}$ to $300 \mathrm{mM}$ stepwise gradient of imidazole until the protein was eluted. The purified proteins were checked for homogeneity in $12.5 \%$ SDSPAGE and quantified by the BCA method (BCA Thermo Scientific Pierce, Rockford, IL, USA) according to the manufacturer's recommendations.

\section{Recombinant proteins}

Eight recombinant proteins, designed based on the domains of the Lig proteins, were employed in this study: LigB [582-947aa] from L. interrogans serovar Pomona, L. interrogans serovar Copenhageni and L. kirschneri serovar Gryppotyphosa, LigB [131-649aa] from L. interrogans serovar Copenhageni, $L$. interrogans serovar Canicola and L. kirschneri serovar Gryppotyphosa, LigA [6251224aa] from $L$. interrogans serovar Copenhageni and LipL32 [1-272aa] from L. interrogans serovar Copenhageni. These fragments were cloned, expressed in Escherichia coli expression system and purified by affinity chromatography as described above.

\section{Multi-antigen print immunoassay}

The assay was performed as described previously [23]. Briefly, antigens were immobilized on a nitrocellulose membrane (Schleicher \& Schuell, Keene, N.H.) so that each strip contained $100 \mathrm{ng}$ of each of the proteins. Phosphate buffer saline was spotted on the nitrocellulose membrane as a negative control reaction (blank). A semi-automatic micro-aerolization device (Automatic TLC Sampler 4, CAMAG, Muttenz, Switzerland) was used to generate parallel bands with no visible marks. The membrane was cut into $0.4 \mathrm{~cm}$ wide strips perpendicularly to the antigen bands. Protein A was added as a control band of antigen-antibody reaction. The strips were blocked overnight with $4 \%$ reduced-fat bovine milk diluted in $0.05 \%$ PBS Tween 20 (Sigma-Aldrich) and then incubated for $2 \mathrm{~h}$ at room temperature with individual serum samples (diluted 1:400 in blocking solution) and $150 \mathrm{ug} / \mathrm{ml}$ of E. coli extract. After washing, the strips were incubated for $1 \mathrm{~h}$ with alkaline phosphatase-labeled anti-dog IgM antibody (Alkaline Phosphatase Dog Conjugated Antibody IgM, Bethyl Laboratories, TX, USA) diluted 1:50,000 in 0.25\% BSA-0.05\% PBS Tween 20 (Sigma-Aldrich). After washing, the strips were incubated with a substrate for alkaline phosphatase (Western Blue Stabilized Substrate for Alkaline Phosphatase, Promega, WI, USA) for 10-15 minutes and the reaction was stopped with distilled water. The reactivity was quantified by densitometry (Bio-Rad GS-800 Calibrated Densitometer, Hercules, CA, USA) and data analysis was performed with Quantity One 1-D Analysis software, Bio-Rad.

\section{Statistical analysis}

For densitometry analysis, relative density was determined by subtracting the background detected for the blank reactions from the reactivity against the recombinant proteins. Cut-off points were established considering the average reactivity of the control samples plus 1.5 standard deviations. Sensitivity and specificity were calculated and defined for each control group individually as well as in combination. Receiver operating characteristic (ROC) curves were made with the "ROCR" R package in the $\mathrm{R}$ environment using the "leave one out crossvalidation" (LOOCV) approach. ROC graphs were created by plotting the true positive rate (sensitivity) against the false positive rate (specificity) at various threshold settings in order to illustrate the recombinant proteins diagnostic performance, which was assessed by the area under the curve (AUC).

\section{Competing interests}

The authors declare that they have no competing interests.

\section{Authors' contributions}

ST performed the experiments, analyzed the data, wrote the paper; CLA analyzed the data, wrote the paper; AlK contributed reagents/materials; WL conceived and designed the experiments, contributed reagents/materials, wrote the paper; MAM conceived and designed the experiments, contributed reagents/materials, wrote the paper. All authors read and approved the final manuscript.

\section{Acknowledgments}

This study was funded by National Council for Scientific and Technological Development (CNPq), Ministry of Science and Technology, Brazil, Bio-Manguinhos and Oswaldo Cruz Foundation, Brazilian Ministry of Health and the National Institutes of Health (R01 Al052473, U01 Al088752, R01 TW009504, D43TW00919). The authors would like to thank LATED - Bio-Manguinhos (FIOCRUZ), Ana Paula Loureiro, Ariel Director and Gabriel Martins - LABV - UFF and all veterinarians who participated directly or indirectly in this study. WL and MAM are CNPq.

\section{Author details}

${ }^{1}$ Laboratory of Veterinary Bacteriology, Department of Microbiology and Parasitology, Universidade Federal Fluminense, Niterói, RJ, Brazil. 2 Fiocruz, Bio-Manguinhos, Laboratory of Recombinant Technology, Avenida Brasil, 4365, Manguinhos, 21045-900 Rio de Janeiro, RJ, Brasil. ${ }^{3}$ School of Public Health, Department of Epidemiology of Microbial Diseases, Yale University, 60 College Street, Downtown, 06510 New Haven, USA.

Received: 12 July 2014 Accepted: 24 November 2014

Published online: 03 December 2014

\section{References}

1. Ko Al, Goarant C, Picardeau M: Leptospira: the dawn of the molecular genetics era for an emerging zoonotic pathogen. Nat. Rev. Microbiol. 2009, 7(10):736-747. 
2. Sykes JE, Hartmann K, Lunn KF, Moore GE, Stoddard RA, Goldstein RE: 2010 ACVIM small animal consensus statement on leptospirosis: diagnosis, epidemiology, treatment, and prevention. J. Vet. Intern. Med. 2011, 25(1):1-13.

3. Martins G, Lilenbaum W: The panorama of animal leptospirosis in Rio de Janeiro, Brazil, regarding the seroepidemiology of the infection in tropical regions. BMC Vet. Res. 2013, 9(1):237.

4. Adler B, de la Peña MA: Leptospira and leptospirosis. Vet. Microbiol. 2010, 140(3-4):287-296

5. La-Ard A, Amavisit P, Sukpuaram T, Wajjwalku W: Evaluation of recombinant Lig antigen-based ELISA for detection of leptospiral antibodies in canine sera. Southeast Asian J. Trop. Med. Public Health 2011, 42(1):128-137.

6. Abdoel TH, Houwers DJ, van Dongen AM, Adesiyun AA, Jiménez-Coelloe M, Cardoso L, Suepaul SM, Ortega-Pacheco A, Smits HL: Rapid test for the serodiagnosis of acute canine leptospirosis. Vet. Microbiol. 2011, 150(1-2):211-213.

7. Lessa-Aquino C, Borges Rodrigues C, Pablo J, Sasaki R, Jasinskas A, Liang L, Wunder EA, Ribeiro GS, Vigil A, Galler R, Molina D, Liang X, Reis MG, Ko Al, Medeiros MA, Felgner PL: Identification of seroreactive proteins of Leptospira interrogans serovar copenhageni using a high-density protein microarray approach. PLoS Negl. Trop. Dis. 2013, 7(10):e2499.

8. Croda J, Ramos JG, Matsunaga J, Queiroz A, Homma A, Riley LW, Haake DA, Reis MG, Ko Al: Leptospira immunoglobulin-like proteins as a serodiagnostic marker for acute leptospirosis. J. Clin. Microbiol. 2007, 45(5):1528-1534.

9. Nabity SA, Ribeiro GS, Aquino CL, Takahashi D, Damião AO, Gonçalves AH, Miranda-Filho DB, Greenwald R, Esfandiari J, Lyashchenko KP, Reis MG, Medeiros MA, Ko Al: Accuracy of a dual path platform (DPP) assay for the rapid point-of-care diagnosis of human leptospirosis. PLOS Negl. Trop. Dis. 2012, 6(11):e1878.

10. Ye C, Yan W, McDonough PL, McDonough SP, Mohamed H, Divers TJ, Chang YF, Yang Z: Serodiagnosis of equine leptospirosis by enzyme-linked immunosorbent assay using four recombinant protein markers. Clin. Vaccine Immunol. 2014, 21(4):478-483.

11. McBride AJ, Cerqueira GM, Suchard MA, Moreira AN, Zuerner RL, Reis MG, Haake DA, Ko Al, Dellagostin OA: Genetic diversity of the Leptospiral immunoglobulin-like (Lig) genes in pathogenic Leptospira spp. Infect. Genet. Evol. 2009, 9(2):196-205.

12. Dellagostin OA, Grassmann AA, Hartwig DD, Félix SR, da Silva É, McBride AJ: Recombinant vaccines against leptospirosis. Hum Vaccin 2011, 7(11):1215-1224.

13. Lottersberger J, Guerrero SA, Tonarelli GG, Frank R, Tarabla H, Vanasco NB: Epitope mapping of pathogenic Leptospira LipL32. Lett. Appl. Microbiol. 2009, 49(5):641-645.

14. Pinne M, Haake DA: LipL32 Is a Subsurface Lipoprotein of Leptospira interrogans: presentation of new data and reevaluation of previous studies. PLoS One 2013, 8(1):e51025.

15. Flannery B, Costa D, Carvalho FP, Guerreiro H, Matsunaga J, Da Silva ED, Ferreira AG, Riley LW, Reis MG, Haake DA, Ko Al: Evaluation of recombinant Leptospira antigen-based enzyme-linked immunosorbent assays for the serodiagnosis of leptospirosis. J. Clin. Microbiol. 2001, 39(9):3303-3310.

16. Guerreiro H, Croda J, Flannery B, Mazel M, Matsunaga J, Galvão Reis M, Levett PN, Ko Al, Haake DA: Leptospiral proteins recognized during the humoral immune response to leptospirosis in humans. Infect. Immun. 2001, 69(8):4958-4968.

17. Cullen PA, Cordwell SJ, Bulach DM, Haake DA, Adler B: Global analysis of outer membrane proteins from Leptospira interrogans serovar Lai. Infect. Immun. 2002, 70(5):2311-2318.

18. Hauk P, Macedo F, Romero EC, Vasconcellos SA, de Morais ZM, Barbosa AS, Ho PL: In LipL32, the major leptospiral lipoprotein, the $C$ terminus is the primary immunogenic domain and mediates interaction with collagen IV and plasma fibronectin. Infect. Immun. 2008, 76(6):2642-2650.

19. Hamond C, Martins G, Lilenbaum W, Medeiros MA: PCR detection of leptospiral carriers among seronegative horses. Vet. Rec. 2012, 171(4):105-106.

20. Juvet F, Schuller S, O'Neill EJ, O'Neill PA, Nally JE: Urinary shedding of spirochaetes in a dog with acute leptospirosis despite treatment. Vet. Rec. 2011, 168(21):564.
21. Oliveira Lavinsky M, Said RA, Strenzel GM, Langoni H: Seroprevalence of anti-Leptospira spp. antibodies in dogs in Bahia, Brazil. Prev Vet Med 2012, 106(1):79-84.

22. (2012) O: Manual of diagnostic tests and vaccines for terrestrial animals. In., vol. 6ath edn. World Organisation for Animal Health, Paris; 2012.

23. Lyashchenko KP, Singh M, Colangeli R, Gennaro ML: A multi-antigen print immunoassay for the development of serological diagnosis of infectious diseases. J. Immunol. Methods 2000, 242(1-2):91-100.

doi:10.1186/s12917-014-0288-2

Cite this article as: Thomé et al:: Identification of immunodominant antigens in canine leptospirosis by Multi-Antigen Print ImmunoAssay (MAPIA). BMC Veterinary Research 2014 10:288.

\section{Submit your next manuscript to BioMed Central and take full advantage of:}

- Convenient online submission

- Thorough peer review

- No space constraints or color figure charges

- Immediate publication on acceptance

- Inclusion in PubMed, CAS, Scopus and Google Scholar

- Research which is freely available for redistribution

Submit your manuscript at www.biomedcentral.com/submit
C Biomed Central 